\title{
TRENDS OF CORONARY ARTERY DISEASE IN KHYBER PAKHTUNKHWA, PAKISTAN: A RETROSPECTIVE STUDY
}

\author{
Sher Bahadar Khan', Syed Abid Habib ${ }^{1 \otimes}$, \\ Muhammad Saad Jibran', Ihsan Ali'
}

\begin{abstract}
OBJECTIVE: To determine the frequency of new coronary artery disease (CAD) cases during the years 2015,2016 and 2017 in patients presenting to a cardiology clinic and to look for its current trends in Khyber Pakhtunkhwa (KP), Pakistan.

METHODS: This descriptive study was conducted in a private clinic of interventional cardiologist, based in Lady Reading Hospital, Peshawar, Pakistan from January to March 2018 . We retrospectively analyzed the echocardiography data and reviewed clinical records from January 2015 to December 2017 and identified cases of incident CAD based on regional wall motion abnormalities on echo. SPSS V20.0 was used for analysis. We applied the unpaired t-test to look for an increasing trend in CAD between 2015-2016, 2016-2017 and 2015 through 2017.
\end{abstract}

RESULTS: A total of 3865 patients of incident coronary artery disease were identified from January 2015 to December 2017. The number of incident CAD patients was 998 in 2015, 1362 in 2016 and 1505 in 2017. We applied the unpaired t-test on the number of post myocardial infarction patients for an increasing trend in 2015 vs 2016,2016 vs 2017 and 2015 vs 2017 which showed a p-value of $<0.00 \mathrm{I}, 0.96 \mathrm{I}$ and $<0.00 \mathrm{I}$ respectively.

CONCLUSION: CAD is on the rise in KP over the past 3 years and attention needs to be paid to risk factor control and health education in addition to improvement in the health system to prevent this trend from getting out of control among the population of KP.

KEY WORDS: Coronary Artery Disease (MeSH); Regional wall motion abnormality (Non-MeSH); Echocardiography (MeSH); Myocardial Infarction (MeSH), Khyber Pakhtunkhwa (Non-MeSH); Pakistan (MeSH).

THIS ARTICLE MAY BE CITED AS: Khan SB, Habib SA, Jibran MS, Ali I. Trends of coronary artery disease in Khyber Pakhtunkhwa, Pakistan: a retrospective study. Khyber Med Univ J 2019;।I(4):214-7. DOI: 10.35845/kmuj.2019.18507

\section{INTRODUCTION}

schemic heart disease is a global epidemic and is a major cause of death and disability around the world.' Once considered a disease of the developed world, changing world demographics have placed it as a major concern in the developing countries at the turn of the century. ${ }^{2}$ Globally, the prevalence of coronary artery disease (CAD) is showing a declining trend in high- income countries due to higher government spending on awareness programs, educational activities, better understanding of disease processes and eventually treatment strategies. Conversely, we have seen a rise in the global burden of CAD in South Asia, Eastern Europe and Southeast Asia. Although the reasons for this rise are complex and multifactorial, we have ample evidence to believe that urban migration, a growing middle class and
I. Cardiology Unit, Medical Teaching Institute Lady Reading Hospital, Peshawar, Pakistan. Email区: docsyedabid@gmail.com Contact \#: +92-333-9884246

Date Submitted:

July II, 2018

Date Revised:

October 22, 2019

Date Accepted:

October 23, 2019

better income lead to adoption of an unhealthy lifestyle which is leading to a rising number of diabetics, hypertensives and smokers in these countries. ${ }^{5,6}$ With a growing trend towards urban migration and a growing middle-class population, it is not surprising that the incidence of CAD is increasing in Pakistan and the situation is said to get worse in the coming decades.

We planned this study to determine frequency of new CAD cases during the years 2015, 2016 and 2017 in patients presenting to a cardiology clinic and to look for its current trends in Khyber Pakhtunkhwa (KP), Pakistan.

\section{METHODS}

This retrospective descriptive study conducted from January 2018 to March 2018. We retrosepctively analyzed the clinical records, history and echocardiography data of a private cardiology clinic of an interventional cardiologist based in Lady Reading Hospital, Peshawar, Pakistan from January 2015 to December 2017. While selecting patients who had a new myocardial infarction (MI) retrospectively, we reviewed past records of history, ECG and cardiac enzymes where available (NOT available in all cases). But in all cases, history of recent $\mathrm{Ml}$ and detailed echo records were present in our computer database. Therefore, we confirmed the history of MI with regional wall motion abnormalities on echo to identify new cases of MI. After a careful evaluation of history, clinical records and echo data, cases of newly diagnosed CAD were identified on the basis of history and regional wall motion abnormalities seen on echo in patients who recently had an MI. Regional wall motion abnormalities (RWMA) on echocardiography were 
TABLE I: BASELINE CHARACTERISITICS OF THE STUDY POPULATION

\begin{tabular}{|c|c|c|c|c|}
\hline \multicolumn{2}{|c|}{ Variable } & Year 2015 & Year 2016 & Year 2017 \\
\hline \multicolumn{2}{|c|}{ Age (years) } & $58.2 \pm 11.05$ & $55.7 \pm 15.9$ & $66.6 \pm 16.4$ \\
\hline \multicolumn{2}{|c|}{ No. of patients (n) } & 998 & 1362 & 1505 \\
\hline \multicolumn{2}{|l|}{ Gender } & $279(28 \%)$ & $476(35 \%)$ & $617(41 \%)$ \\
\hline \multirow{2}{*}{ Dyspnea } & NYHA III & $169(17 \%)$ & $177(13 \%)$ & $165(11 \%)$ \\
\hline & NYHA IV & $230(23 \%)$ & $490(36 \%)$ & $286(19 \%)$ \\
\hline \multicolumn{2}{|c|}{ Chest pain } & $878(88 \%)$ & $1239(91 \%)$ & 1339 (89\%) \\
\hline \multicolumn{2}{|c|}{ Orthopnea } & $349(35 \%)$ & 531 (39\%) & $557(37 \%)$ \\
\hline \multicolumn{2}{|c|}{ Paroxysmal Nocturnal Dyspnea } & $99(10 \%)$ & 191 (14\%) & $466(31 \%)$ \\
\hline
\end{tabular}

TABLE II: ECHOCARDIOGRAPHY PARAMETERS OF THE STUDY POPULATION

\begin{tabular}{|c|c|c|c|c|}
\hline \multicolumn{2}{|c|}{ Variable } & $\begin{array}{c}\text { Year } 2015 \\
\text { (n: 998) }\end{array}$ & $\begin{array}{c}\text { Year } 2016 \\
\text { (n: I362) }\end{array}$ & $\begin{array}{c}\text { Year } 2017 \\
\text { (n: I505) }\end{array}$ \\
\hline \multicolumn{2}{|c|}{ LVED $(\mathrm{cm})$} & $4.8 \pm 1.7$ & $5.1 \pm 1.5$ & $5.0 \pm 1.1$ \\
\hline \multicolumn{2}{|c|}{ LVESD $(\mathrm{cm})$} & $3.7 \pm 0.6$ & $3.1 \pm 1.1$ & $2.9 \pm 1.6$ \\
\hline \multicolumn{2}{|l|}{ FS (\%) } & $21.9 \pm 5.4$ & $28.1 \pm 8.1$ & $30.7 \pm 7.7$ \\
\hline \multicolumn{2}{|l|}{$\mathrm{EF}(\%)$} & $44.3 \pm 9.4$ & $54.3 \pm 12.04$ & $58.1 \pm 15.7$ \\
\hline \multirow{4}{*}{ RWMA } & Anterior & $439(44 \%)$ & $626(46 \%)$ & 767 (5I\%) \\
\hline & Inferior & 79 (8\%) & $136(10 \%)$ & $105(7 \%)$ \\
\hline & Lateral & $229(23 \%)$ & 231 (I7\%) & 346 (23\%) \\
\hline & Mixed & $249(25 \%)$ & 367 (27\%) & $286(19 \%)$ \\
\hline \multicolumn{2}{|l|}{ VSD } & $20(2 \%)$ & $21(1.6 \%)$ & $13(0.9 \%)$ \\
\hline
\end{tabular}

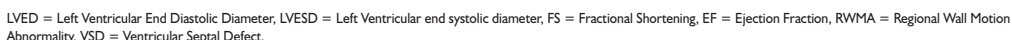

described as either hypokinesia (reduced endocardial inward movement and systolic wall thickening), akinesia (absence of endocardial inward movement and systolic wall thickening) or dyskinesia (outward wall movement in systole with absent wall thickening). Cases were excluded if they had a previous history of $\mathrm{Ml}$ at least a year before presenting to the clinic to avoid doubling the same patient in two consecutive years in our eventual analysis. All analysis was done with SPSS V20.0. Continuous and categorical variables were described as mean $\pm S D$ and frequencies/percentages respectively. We applied the unpaired $t$ test to look for an increasing trend in CAD in 2015 vs 2016,2016 vs 2017 and 2015 vs 2017.

\section{RESULTS}

A total of 3865 patients of incident coronary artery disease were identified from January 2015 to December 2017 with a mean age of $58.2 \pm 11.05$ in 2015 , $55.7 \pm 15.9$ in 2016 and $66.6 \pm 16.4$ years in 2017. The number of incident CAD patients was 998 in 2015, 1362 in
2016 and 1505 in 2017 with an increasing trend seen in the female population which rose from 279 (28\%) in $2015,476(35 \%)$ in 2016 to 617 $(41 \%)$ in 2017. Mean Left Ventricular Ejection Fraction (LVEF) was 44.3 \pm 9.4 in $2015,54.3 \pm 12.04$ in 2016 and $58.1 \pm 15.7$ in 2017. The predominant RWMA was seen in anterior region with $44 \%$ in $2015,46 \%$ in 2016 and $51 \%$ in 2017. VSR was seen in $2 \%$ patients in $2015,1.6 \%$ in 2016 and $0.9 \%$ in 2017 . All baseline characteristics are given in Table I. Echo parameters of included patients are given in Table II. We applied the unpaired $t$ test on the number of new $\mathrm{MI}$ patients for an increasing trend between 2015-2016, 2016-2017 and $2015-2017$ the $p$ value turned out to be $<0.001,0.96$ I and $<0.00$ I respectively.

\section{DISCUSSION}

In this study, the number of CAD patients was steadily increasing from $2015(n=998)$ to $2016(n=1362)$ and $2017(n=1505)$ in Khyber Pakhtunkhwa province of Pakistan.
In the developed high-income countries, we have seen a decline in CAD mortality in the period since 19807 due to better government spending on risk factor control, educational activities for mass awareness, campaigns on the media, discouraging smoking by heavily taxing the cigarette industry, improvements in medical care and treatment strategies. ${ }^{7}$

"In addition, high-income countries are spending more money on rehabilitation programs for established CAD patients. Conversely, developing countries and countries in the low-to middle-income economic regions including South Asia have experienced a paradigm shift as far as incidence and mortality of CAD is concerned over the past 20 years. ${ }^{2,3,7,12,13}$

Some of the major factors responsible for this trend in South Asia are a lack of health awareness, an adoption of lifestyles that are unhealthy, poor and suboptimal dietary habits, higher prevalence of such factors as DM and hypertension and most importantly, poor health infrastructure in the region. ${ }^{14-17}$ Particularly, poor dietary habits such as consumption of high trans-fat diet, lack of whole grains and fruits in daily diet and a poor vegetable intake have been found responsible for worsening CAD trends in Pakistan. Pakistan also has the highest proportion of outdoor air pollution, particularly in urban regions in whole of South Asia. ${ }^{18}$

In our study, we found that the incidence of CAD was on the rise in Khyber Pakhtunkhwa province of Pakistan from 2015 through 2017. Unsurprisingly, we also noted a rising trend of CAD among women of Khyber Pakhtunkhwa Pakistan with $28 \%$ in $2015,35 \%$ in 2016 and $41 \%$ in 2017 . Whether this was because of a decreasing trend in males is not clear. However, even if we analyze the absolute numbers, there is an increase in the number of female patients presenting with new $C A D$.

We believe it must have been due to a rising trend in females because global investigators have reported a rising trend of CAD in the female population. ${ }^{3,6}$ Some novel risk factors have been shown to be responsible for this rise in addition to the traditional risk 
factors. Jibran MS, et al. reported a positive correlation between NAFLD and incident CAD in our population. ${ }^{19}$

The population of Khyber Pakhtunkhwa has increased from 2015 to 2017. Indeed, this could influence the incidence of CAD in our population. But, we did not take the increase in population into account because it was not a study on the "incidence" of CAD. Our study shows an increasing trend in CAD over the years. Therefore, our data only shows an increasing trend. It is not obvious whether this trend was because of an increase in population of the province or any other demographic variable, which needs to be determined in large scale epidemiological studies. In light of this evidence, we need more government spending and attention for mass awareness, promotion of positive lifestyle, promotion of risk factor control and eventually rehabilitation of CAD patients before it's too late.

\section{CONCLUSION}

Coronary artery disease is on the rise in Khyber Pakhtunkhwa, Pakistan over the past three years and attention needs to be paid to risk factor control and health education in addition to improvement in the health system to prevent this trend from getting out of control among the population of KP, Pakistan.

\section{REFERENCES}

I. Lozano R, Naghavi M, Foreman K, Lim S, Shibuya K, Aboyans V, et al. Global and regional mortality from 235 causes of death for 20 age groups in 1990 and 2010: a systematic analysis for the Global Burden of Disease Study 2010. Lancet 2012 Dec 15;380(9859): 2095-I28. DOI: 10.1016/S0I406736(I2)61728-0.

2. Leeder S, Raymond S, Greenberg H, Liu H, Esson K. A race against time: the challenge of cardiovascular disease in developing economies. New York: Trustees of Columbia University 2004. [Cited on: July II, 2018]. Available from URL: https://www.earth.columbia.edu/n ews/2004/images/raceagainsttime_ FINAL_05 I I04.pdf.
3. Shepard D, Vande-Zanden A, Moran A, Naghavi M, Murray C, Roth G. Ischemic heart disease worldwide, I 990 to 20 I 3: estimates from the global burden of disease study 2013.Circ Cardiovasc Qual Outcomes 2015 Jul I;8(4):455-6. DOI: $10.1161 / C I R C O U T C O M E S$. II5.002007.

4. Kim AS, Johnston SC. Global variation in the relative burden of stroke and ischemic heart disease. Circulation 20I I Jul 19; I24(3):31423 . D O I: $|0.1| 6 \mid$ | CIRCULATIONAHA. I I I.018820.

5. Yakoob MY, Micha R, Khatibzadeh S, Singh GM, Shi P, Ahsan H, et al. Impact of dietary and metabolic risk factors on cardiovascular and diabetes mortality in South Asia: Analysis from the 2010 global burden of disease study. Am J Public Health 2016 Dec; 106(I2):2II3-25. DOI: I0.2 I05/AJPH.2016.303368.

6. Moran $A E$, Tzong KY, Forouzanfar $\mathrm{MH}$, Roth GA, Mensah GA, Ezzati $M$, et al. Variations in ischemic heart disease burden by age, country, and income: the Global Burden of Diseases, Injuries, and Risk Factors 2010 study. Glob Heart 2014 Mar I;9(I):9I-9. DOI: I0.1016/j.gheart. 2013.12.007

7. Moran AE, Forouzanfar $\mathrm{MH}$, Flaxman AD, Roth G, Mensah G, Ezzati $M$, et al. Temporal trends in ischemic heart disease mortality in 21 world regions, 1980-2010: The global burden of disease 2010 study. J Am Coll Cardiol 2010;61(10 Supplement):EI407. DOI: 10.1016/ S0735-1097(I3)6 |407-2.

8. Tunstall-Pedoe $H$, Vanuzzo $D$, Hobbs M, Mähönen M, Cepaitis Z, Kuulasmaa K, et al. WHO MONICA Project. Estimation of contribution of changes in coronary care to improving survival, event rates, and coronary heart disease mortality across the WHO MONICA Project populations. Lancet $2000 \mathrm{Feb}$ 26;355(9205):688-700. DOI: 10. |0|6/S0|40-6736(99) | | |8|-4.

9. Kuulasmaa $\mathrm{K}$, Tunstall-Pedoe $\mathrm{H}$, Dobson A, Fortmann S, Sans S, Tolonen $\mathrm{H}$, et al. Estimation of contribution of changes in classic risk factors to trends in coronaryevent rates across the WHO MONICA Project populations. The Lancet 2000 Feb 26;355(9205):67587. DOI: I0.I0I6/S0I40-6736(99) $11180-2$.

10. Ford ES, Ajani UA, Croft JB, Critchley JA, Labarthe DR, Kottke $\mathrm{TE}$, et al. Explaining the decrease in US deaths from coronary disease, 1980-2000. N Engl J Med 2007 Jun 7;356(23):2388-98. DOI: 10.1056/ NEJMsa053935.

II. Di-Cesare M, Bennett JE, Best N, Stevens GA, Danaei G, Ezzati M. The contributions of risk factor trends to cardiometabolic mortality decline in 26 industrialized countries. Int J Epidemiol 2013 Jun I;42(3):838-48. DOI: 10.1093/ ije/dyt063.

12. Jafar TH, Gandhi M, Naheed A, Jehan I, De Silva HA, Finkelstein E, et al. P6256 Large cardiovascular risk burden in rural Bangladesh, Pakistan, and Sri Lanka: design and preliminary findings in a Cluster Randomized Controlled Trial (COBRA-BPS). Eur Heart J 2017 Aug I;38(suppl_I):ehx493.P6256. DOI: 10.1093/eurheartj/ehx 493.P6256.

13. Huffman MD, Rao KD, PichonRiviere A, Zhao D, Harikrishnan S, Ramaiya K, et al. A cross-sectional study of the microeconomic impact of cardiovascular disease hospitalization in four low-and middle-income countries. PLoS One 20I I Jun I4;6(6):e2082 I. DOI: I0.137|/journal.pone.002082 I

14. Reddy KS. Cardiovascular disease in non-Western countries. N Engl J Med 2004 Jun 10;350(24):2438-40. DOI: I0.1056/NEJMp048024.

I5. Popkin BM, Adair LS, Ng SW. Global nutrition transition and the pandemic of obesity in developing countries. Nutr Rev 2012 Jan;70(I):3-2I. DOI: I0.IIII/ j. 1753-4887.201।.00456.x.

16. Joshi P, Islam S, Pais P, Reddy S, Dorairaj $P$, Kazmi K, et al. Risk factors for early myocardial infarction in South Asians compared 
with individuals in other countries. JAMA 2007 Jan 17;297(3):286-94. DOI: I0.100I/jama.297.3.286.

17. Danaei G, Finucane MM, Lu Y, Singh GM, Cowan MJ, Paciorek CJ, et al. National, regional, and global trends in fasting plasma glucose and diabetes prevalence since 1980: systematic analysis of health examination surveys and epidemiological studies with 370 country-years and 2.7 million participants. Lancet $20 \mathrm{II}$ Jul $2 ; 378(9785): 31-40$. DOI: $10.1016 / 50140-6736$ (II)60679-X.

18. Yamamoto SS, Phalkey R, Malik AA. A systematic review of air pollution as a risk factor for cardiovascular disease in South Asia: limited evidence from India and Pakistan.
Int J Hyg Environ Health 2014 Mar I;2I7(2-3): I33-44. DOI: 10.1016/j. ijheh.20I3.08.003.

19. Jibran MS, Zahid ZU, Shawana, Gul AM, Khan SB, Irfan M. Association of nonalcoholic fatty liver disease with coronary artery disease. Pak Heart J 2017;50(04):248-52.

\section{AUTHORS' CONTRIBUTIONS}

Following authors have made substantial contributions to the manuscript as under:

SBK \& SAH: Conception and study design, drafting the manuscript, critical review, final approval of the version to be published

MSJ \& IA: Acquisition, analysis and interpretation of data, drafting the manuscript, final approval of the version to be published

Authors agree to be accountable for all aspects of the work in ensuring that questions related to the accuracy or integrity of any part of the work are appropriately investigated and resolved.

\begin{tabular}{|c|}
\hline CONFLICT OF INTEREST \\
Authors declared no conflict of interest \\
GRANT SUPPORT AND FINANCIAL DISCLOSURE \\
NIL
\end{tabular}

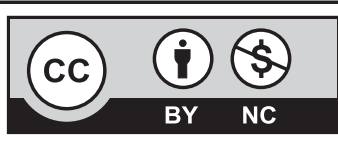

This is an Open Access article distributed under the terms of the Creative Commons Attribution-Non Commercial 2.0 Generic License.

KMUJ web address: www.kmuj.kmu.edu.pk

Email address: kmuj@kmu.edu.pk 